\title{
A MULTIDISCIPLINARY LEARNING EXPERIENCE FOR EDUCATION IN ACCESSIBILITY
}

\author{
Beth Robertson ${ }^{1}$, Adrian D. C. Chan ${ }^{2}$ \\ ${ }^{1}$ Department of History, Carleton University \\ ${ }^{2}$ Department of Systems and Computer Engineering, Carleton University \\ adrian.chan@carleton.ca
}

\begin{abstract}
This paper argues that accessibility is both a complex issue and one in which engineering students would deeply benefit from learning more about due to mounting legislation and demand. Engineers can play an important role in creating a more inclusive society, yet questions remain as to how to instill knowledge of accessibility effectively in the classroom.

To answer these questions, the authors explore and draw preliminary conclusions from a multidisciplinary learning experience they designed by which two upper level undergraduate courses from engineering and history were joined on separate occasions to provide some education in accessibility.

Although crafting and delivering this experience posed some challenges, the authors believe that this multidisciplinary approach generally enriched the learning experience for students, exposing them to a broader perspective, and in particular the historical context for accessibility initiatives and the lived experience of people with disabilities.
\end{abstract}

Keywords: accessibility, engineering, education, history, multidisciplinary, experience, inclusive, pedagogy.

\section{INTRODUCTION}

There is a growing interest and need for education in accessibility, including the area of information and communications technology (ICT) [1]-[4]. There is an increased awareness from a human rights perspective (e.g., United Nations Convention on the Rights of Persons with Disabilities [5]) and increase legislative requirements (e.g., Accessibility for Ontarians with Disabilities Act (AODA) [6], proposed federal Accessible Canada Act [7]). In addition, there are also economic advantages with increased accessibility and inclusion being recognized [8]. However, despite an increased interest and need for education in accessibility, most students in engineering, computer science, information systems, and information technology are not being taught about accessibility $[3,4]$.
Accessibility can be considered a 'wicked problem', which is characterized as having "incomplete, contradictory, and changing requirements that are often difficult to recognize... [and] complex interdependencies" [9]. While engineers can play an important role, the pursuit of an accessible and inclusive society requires a multidisciplinary approach. Technological approaches to accessibility are limited, after all, if they are not informed by a broader social and historical analysis of persisting attitudinal, cultural and economic barriers [10].

The benefits of a multidisciplinary approach had already been experienced in our research related to disability and accessibility. The Carleton University Disability Research Group (CUDRG; https://cudisabilityresearchgroup.wordpress.com/) was founded in 2013 by three faculty members: Dr. Adrian Chan (co-author), Department of Systems and Computer Engineering, Faculty of Engineering and Design, Dr. Roy Hanes, School of Social Work, Faculty of Public Affairs, and Dr. Dominique Marshall, Department of History, Faculty of Arts and Social Sciences. Dr. Beth Robertson (co-author) is also a member of CURDG and an instructor in the Department of History, Faculty of Arts and Social Sciences. The objective of the CUDRG "is to raise awareness, as well as questions about societal understandings of disability and technology by creating virtual exhibits and other collaborative, multidisciplinary research outputs that take a participatory approach to telling the histories of activists, users, and innovators who contribute to a more inclusive and accessible transnational Canada" [11]. CUDRG has two virtual exhibits: 1) $A$ Wheelchair History of Disability [12], which focuses on the wheelchair and wheelchair users, and 2) Envisioning Technologies [13], which focuses on the historical experiences and technological ingenuity of people who are blind or partially sighted. Physical versions, including a traveling version, of the Envisioning Technologies exhibit were also created, and have been displayed in various locations including: Carleton University, Ottawa Public Library, the Canada Space and Aviation Museum, University of Toronto, Ryerson University, The W. Ross 
Table 1: Course descriptions and enrollments.

\begin{tabular}{|c|c|}
\hline $\begin{array}{l}\text { SYSC4201 Ethics, Research Methods, and } \\
\text { Standards for Biomedical Engineers }\end{array}$ & HIST 3903/TSES 4010 Bodies, Diversities, \\
\hline $\begin{array}{l}\text { Course Description: Ethical theories, } \\
\text { ethical decision-making, biomedical } \\
\text { research ethics: informed consent, } \\
\text { confidentiality, privacy, research ethics } \\
\text { boards; research methods: hypothesis } \\
\text { formulation, data collection, sampling bias, } \\
\text { experimental design, statistical literacy; } \\
\text { regulations for design, manufacture, } \\
\text { certification of medical devices; impact of } \\
\text { technology and research (social, political, } \\
\text { financial). }\end{array}$ & $\begin{array}{l}\text { Course Description: This blended course aims to explore the } \\
\text { complicated historical relationship between bodies and technologies } \\
\text { in Canada and beyond from the 19th to } 21 \text { st centuries. At once } \\
\text { promising and, at times, troubling, this relationship has been forged } \\
\text { through specific understandings of authority, end-users and ethics, } \\
\text { for which important checks and balances have been established, } \\
\text { revised, challenged and negotiated over time. Topics for the course } \\
\text { will range from the evolution of prosthetics and adaptive devices to } \\
\text { nuclear medicine and reproductive technologies. One of the primary } \\
\text { aims of the course would be to interrogate, through the lens of } \\
\text { history, feminist and disability studies, how different conceptions of } \\
\text { the 'normative', as well as diverse bodies and experiences, have } \\
\text { intersected with technological development over time. }\end{array}$ \\
\hline Enrollment: 82 students & 9 stuc \\
\hline
\end{tabular}

Macdonald School, and most recently the University of British Columbia.

Educational toolkits, aimed at teaching primary and secondary school students about accessibility, are being developed using the CUDRG exhibits. These workshops have been piloted at the Enrichment Mini-Courses Program (https://www.emcp-pmce.ca; Grades 8 to 11) and SHAD (https://www.shad.ca/; Grades 10 to 12).

Continuing to expand our initiatives, we attempted to provide a multidisciplinary learning experience for education in accessibility, intersecting an engineering course and a history course on two different occasions. During these joint classes, students from different disciplines were able to interact in small groups and discuss a series of pre-assigned online and reading materials. We sought to explore if and how this multidisciplinary approach might enrich the learning experience for students, exposing them to a broader, more contextualixzed perspective, especially when it came to issues of accessibility and disability.

\section{LEARNING EXPERIENCES}

The two courses that were involved in this multidisciplinary learning experience were (Table 1): 1) SYSC 4201 Ethics, Research Methods, and Standards for Biomedical Engineers, taught by co-author Chan, and 2) HIST 3903/TSES 4010 Bodies, Diversities, and Technologies, taught by co-author Robertson. Albeit from two different disciplines, both courses were nonetheless complementary in that they each emphasized issues of ethics and accessibility. They also were both at more or less the same educational level at the $3^{\text {rd }}$ and $4^{\text {th }}$ year. To combine the two courses, the authors organized two joint sessions, where students from both classes were combined for 1.5 hours. During these classes, student were organized into 16 small groups ( $\sim 6$ students) such that there were students from both classes in each group.

The first joint class Prosthetics, Productivity \& Personhood was held on February 14, 2019. This class involved two readings [14][15] and three online resources, ranging from a series of photographs from the Canadian War Museum, a short film released by the British Ministry of Information in 1943, and an organizational history of the War Amp's [16]-[18]. Referring to these materials and the associated readings, the class lecture and discussion provided students with a contextual explanation of the history of prosthetics, including its more recent incarnations, as well as an introduction to the various models of disabilities that frequently inform the technological development of prosthetic research (e.g., medical model, social model, economic model). In their groups, students were asked to reflect on the following questions:

1. What do you notice about the design of the prosthetics in the Canadian War Museum lantern slides?

2. What do you notice about the users being represented in the Canadian War Museum lantern slides?

3. How are prosthetics and disability presented in the short film "Back to Normal"?

4. How is disability and prosthetics presented in "Our History: The War Amp's"?

5. How do these different representations of prosthetics and disability compare? How are they similar? How are they different?

This first joint class ended with the showing of Dean Kamen's TED Talk Luke, a new prosthetic arm for soldiers [19], with students asked to consider how this TED Talk 
Table 2: Questionnaire.

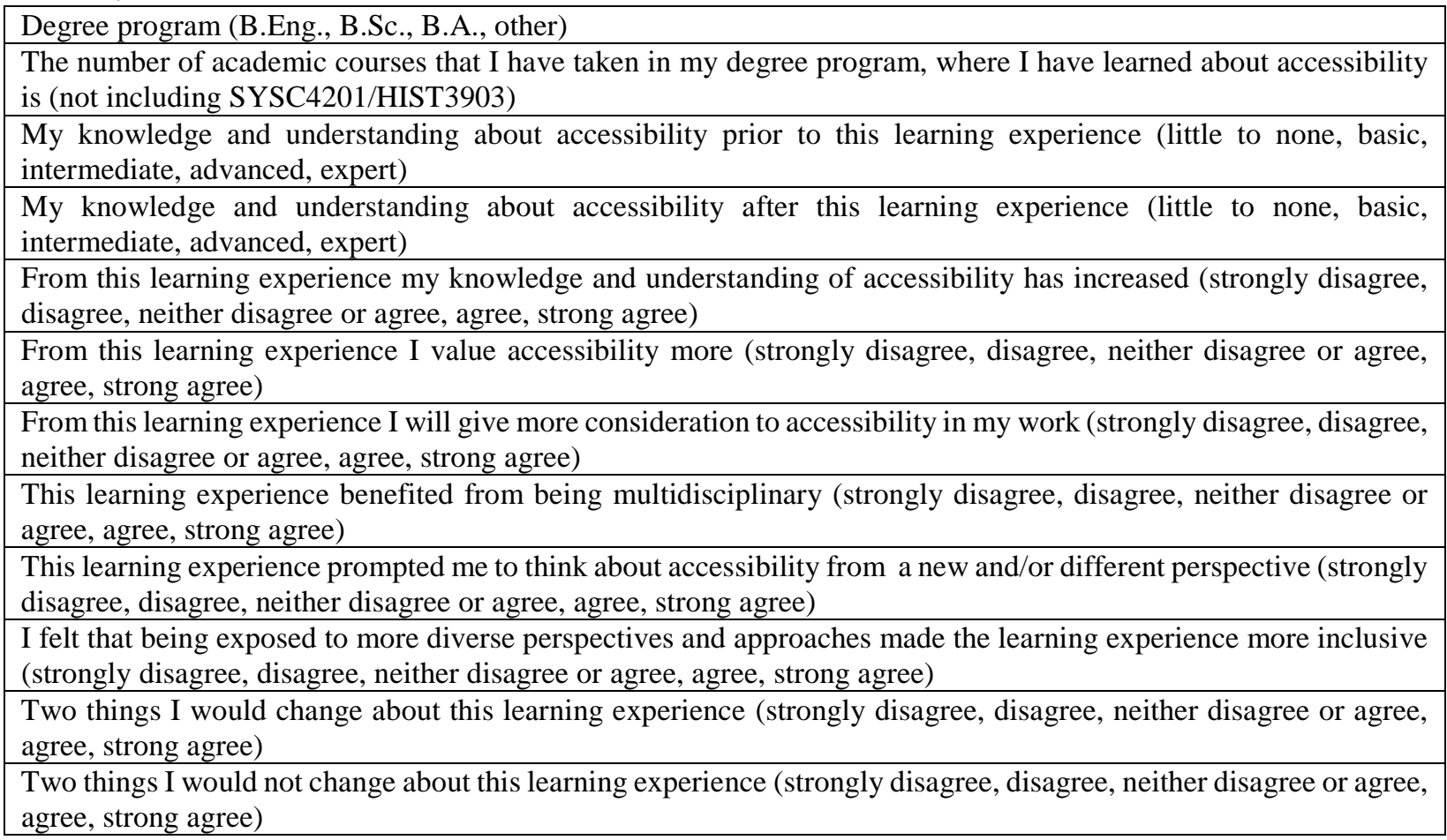

compares to more historical representations of disability and prosthetics, and how it might carry forward or diverge from some of the ideas of disability and prosthetics that existed in the past.

The second joint class Assistive, Adaptive, Inclusive was held on March 14, 2019. This class involved two readings [20][21] and two online resources, one of which was the same virtual exhibit the authors had designed and implemented in previous pedagogical endeavours called Envisioning Technologies. This exhibit, paired with a history of human rights for people with disabilities by the Canadian Human Rights Commission, emphasized the role of advocacy and activism, as well as the lived experiences of people with disabilities, in shaping the evolution of assistive and adaptive technologies, as well as more inclusive approaches to design. [13][22]. The class reviewed the main ideas presented from the first joint class, introduced the concept of accessibility and its various definitions, and presented on the meaning of universal design and inclusive design. A lecture on the intellectual framework of academic accessibility was then delivered by Hollis Pierce, a Masters of Arts in history graduate student, who is also a CUDRG member. Using Carleton University as a case study, this lecture discussed the physical infrastructure, the legislative and intellectual framework through which one can examine accessibility initiatives in the past and more currently. The lecture drew from Pierce's thesis research, as well as his lived experience as a person with a disability. Finally, with one of the physical versions of the Envisioning Technologies exhibit on display, students were asked to reflect upon the following questions in their groups:

1. What are the roles of people with disability in the exhibit episode you explored? (User? Advocate? Designer?)

2. In each episode, what are the barriers that people with disabilities faced and/or attempted to address?

3. How did the technologies attempt to address these barriers?

4. How would you classify each technology discussed in light of the definitions we explored previously of inclusive and universal design as well as accessibility?

5. What model of disability do these technologies reflect - the economic model? The social model? The medical model?

Unfortunately, the timing only left 5 minutes for the small group reflection, which was quite limited; however many students lingered following class to explore the exhibit further and ask questions of the guest lecturer.

\section{QUESTIONNAIRE AND RESULTS}

Students involved in the multidisciplinary learning experiences from the two classes were invited to fill out a questionnaire (Table 2). The questionnaire was filled out 


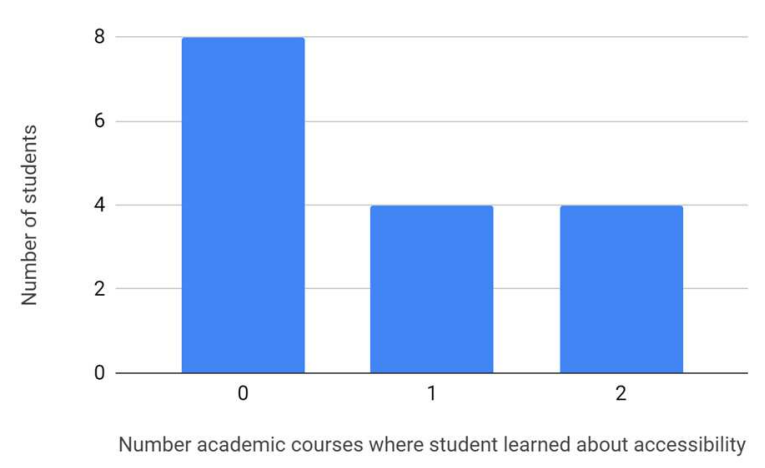

Fig. 1. Number of academic courses where students learned about accessibility.

anonymously. This research was reviewed and cleared by the Carleton University Research Ethics Board.

A total of 16 students completed the questionnaire: 14 students from SYSC 4201 and 2 students from HIST 3903/TSES 4010. Half of the students that responded indicated that this was the first course where they learned about accessibility (Fig. 1); the two HIST 3909/TSES 4010 responses indicated 1 and 2 academic courses where they learned about accessibility, previously. It should be noted that there was an effort a few years ago where accessibility was topic in CCDP 2100 Communication Skills for Engineering Students, a mandatory course for all Carleton University Engineering students. In this course, students were tasked with a team project to design a product to improve accessibility, which students then had the opportunity to submit to the Innovative Designs for Accessibility (IDeA) initiative that was run by the Council of Ontario Universities (currently run by Universities Canada). The topic of accessibility is not used as the main project theme in CCDP 2100 at the present time.

The respondents noted a positive effect on their knowledge and understanding about accessibility from these learning experiences (Fig. 2). In general, there appears to have been a positive effect on both the cognitive and affective learning (Table 3). The affective learning is viewed as an important element in accessibility. Some have noted that teaching accessibility requires teaching empathy [23][24]. Increased empathy, in turn, may help students move from being aware of accessibility barriers to take actions to address such barriers [25].

The benefits of a multidisciplinary approach, while overall positive, scored relatively lower. Based on the written feedback, some of the issues that contributed to this was the learning environment (classroom was a large stadium seating lecture room), the balance in representation (engineering students far outnumbered nonengineering students, and some groups ended up only have engineering students due to absentees), and time for group discussions, which ended up being quite brief and only happened during the two designated joint classes. From the written feedback, the authors conclude that the students appreciated the benefits of having a multidisciplinary perspective but these benefits could have been better realized.

A number of students commented on the importance of having a guest lecturer with lived experience, and appreciated the perspectives and insights he brought. Interactions with people with disabilities and having the lived experiences shared, helps support the teaching of accessibility concepts [4]; in particular, interactions with people with disabilities supports the development of empathy [25].

\section{CONCLUSIONS}

Consistent with previous studies, engineering students appear to have limited opportunities to learn about accessibility within their academic program; this, despite a growing interest and need. We provided students a multidisciplinary learning experience for accessibility, which appeared to have a good impact within two joint 1.5 hour classes.

Table 3: Questionnaire results.

\begin{tabular}{|l|l|l|l|l|l|}
\hline Question & $\begin{array}{c}\text { Strongly } \\
\text { Disagree }\end{array}$ & Disagree & $\begin{array}{c}\text { Neither } \\
\text { disagree or } \\
\text { agree }\end{array}$ & Agree & $\begin{array}{c}\text { Strongly } \\
\text { agree }\end{array}$ \\
\hline $\begin{array}{l}\text { My knowledge and understanding of } \\
\text { accessibility has increased }\end{array}$ & & & $62.5 \%$ & $37.5 \%$ \\
\hline I value accessibility more & & & $31.3 \%$ & $31.3 \%$ & $37.5 \%$ \\
\hline $\begin{array}{l}\text { I will give more consideration to } \\
\text { accessibility in my work }\end{array}$ & & $25 \%$ & $31.3 \%$ & $18.8 \%$ & $25 \%$ \\
\hline Benefited from being multidisciplinary & & $31.3 \%$ & $43.8 \%$ & $25 \%$ \\
\hline $\begin{array}{l}\text { Prompted me to think about accessibility } \\
\text { from a new and/or different perspective }\end{array}$ & & $12.5 \%$ & $25 \%$ & $37.5 \%$ & $25 \%$ \\
\hline $\begin{array}{l}\text { I felt that being exposed to more diverse } \\
\text { perspectives and approaches made the } \\
\text { learning experience more inclusive }\end{array}$ & & & & $37.5 \%$ & $50 \%$ \\
\hline
\end{tabular}


There appeared to be benefits of having the learning experience be multidisciplinary, with each instructor bringing a different perspective to the subject matter. This seems to support the existing literature in this area, which argues that such experiences are necessary to prepare students to "operate in a dynamic, integrative mode of continuous learning and exchanges of ideas and information," especially when faced with more complex problems and issues, of which accessibility is but one [26].

Peer-interactions across disciplinary boundaries were viewed as positive but limited in our implementation. Respondents seemed to indicate that more meaningful integration of the two student bodies (i.e., more than two joint classes, longer small group discussion periods, etc.) would have been beneficial to the learning experience. There are arguably structural and even intellectual barriers to doing so, especially within the current disciplinary model of university course delivery, which other educators have also noted, requiring perhaps a rethinking of the delivery model and pedagogical strategies employed [27].

Combining two classes also adds a layer of logistic complexity (e.g., class scheduling, enrollment balancing) While there is a potential for this type of multidisciplinary approach, therefore, it seems there are nonetheless challenges that require further investigation. Yet even within an imperfect multidisciplinary environment, it would seem that simply having a guest lecturer from a different discipline already adds enormous value to the educational experience. This trial also reaffirms the importance of including the lived experience of people with disabilities, when learning about accessibility.

\section{Acknowledgements}

The authors would like to acknowledge Hollis Pierce and his guest lecture to the multidisciplinary learning experience for education in accessibility.

\section{References}

[1] Shawn Lawton Henry, Shadi Abou-Zahra, and Judy Brewer. 2014. The role of accessibility in a universal web. In Proceedings of the 11th Web for All Conference (W4A'14). ACM, New York, NY, Article 17,4 .

[2] Cynthia Putnam, Maria Dahman, Emma Rose, Jinghui Cheng, and Glenn Bradford, "Best Practices for Teaching Accessibility in University Classrooms: Cultivating Awareness, Understanding, and Appreciation for Diverse Users", ACM Transactions on Accessible Computing, Vol. 8, No. 4, Article 13, 2016.

[3] Kristen Shinohara, Saba Kawas, Andrew J. Ko, and Richard E. Ladner, "Who Teaches Accessibility? A Survey of U.S. Computing Faculty", in Proceedings of the 49th ACM Technical Symposium on Computer Science Education, pp. 197-202, Baltimore MD, USA, 2018.
[4] Legislative Workgroup on Accessibility Concepts in Computer Science, Information Systems and Information Technology Programs in Higher Education, Maryland Department of Disabilities, Final Report of the Study on Accessibility Concepts in Computer Science, Information Systems and Information Technology Programs in Higher Education, August 8, 2017.

[5] UN General Assembly, Convention on the Rights of Persons with Disabilities: resolution / adopted by the General Assembly, 24 January 2007, A/RES/61/106.

[6] Accessibility for Ontarians With Disabilities Act, 2005, SO 2005. Available at https://www.ontario.ca/laws/statute/05a11. Last accessed 2019-01-02.

[7] BILL C-81 An Act to ensure a barrier-free Canada. Available http://www.parl.ca/DocumentViewer/en/42-1/bill/C81/third-reading. Last accessed 2019-01-02.

[8] Kemper et al., Releasing Constraints: Projecting the Economic Impacts of Increased Accessibility in Ontario. Martin Prosperity Institute, 2010.

[9] Wikipedia contributors. "Wicked problem." Wikipedia, The Free Encyclopedia. Wikipedia, The Free Encyclopedia, Dec 14, 2018. Available at https://en.wikipedia.org/wiki/Wicked_problem. Last accessed 2019-01-02.

[10] Langdon et al., Inclusive Designing: joining usability, accessibility and inclusion. New York: Springer, 2012.

[11] Carleton University's Disability Research Group, https://cudisabilityresearchgroup.wordpress.com/. Last accessed 2019-03-18.

[12] Carleton University's Disability Research Group, A Wheelchair History of Disability, https://mobilityhistories.omeka.net. Last accessed 2019-03-18.

[13] Carleton University's Disability Research Group, Envisioning Technologies, https://envisioningtechnologies.omeka.net/. Last accessed 2019-03-18.

[14] Michael J. Lansing, "'Salvaging the Man Power of America': Conservation, Manhood and Disabled Veterans during World War I," Environmental History 14, no.1 (January 2009): 32-57.

[15] David J.A. Foord and Peter Kyberd, "From Design to Research: Upper Limb Prosthetic Research and Development in Canada," Scientia Canadensis: Canadian Journal of the History of Science, Technology and Medicine 38, no.1 (2015): 50-71.

[16] Major Frederick Sypher Burke's lantern slide collection, First World War, Canadian War Museum, Ottawa, Ontario, https://collections.historymuseum.ca/public/objects/co mmon/webmedia.php?irn=5371394 
[17] "Back to Normal" https://www.youtube.com/watch?v=8urUSfs $15 \mathrm{e} 8$

[18] "Our History: The War Amps" https://www.waramps.ca/about-us/history/

[19] https://www.ted.com/talks/dean_kamen_previews_a_n ew_prosthetic_arm?utm_campaign=tedspread\&utm_ medium=referral\&utm_source=tedcomshare

[20] Gregor Wolbring and Natalie Ball, "History of Science and Technology and Canadians with Disabilities," (306-319), Untold Stories: A Canadian Disability History Reader, eds. Nancy Hansen, Roy Hanes and Diane Driedger (Toronto: Canadian Scholars Press, 2018).

[21] Bess Williamson, "Electric Moms and Quad Drivers: People with Disabilities Buying, Making and Using Technology in Postwar America," American Studies 52, no.1 (2012): 5-30.

[22] "Human Rights in Canada: An Historical Perspective: Persons with Disabilities," Canadian Human Rights Commission https://www.chrc-ccdp.gc.ca/historicalperspective/en/browseSubjects/personsDisability.asp

[23] Kimberly Edginton Bigelow "Designing for success: Developing engineers who consider universal design principles," .Journal of Postsecondary Education and Disability, 25(3): 211-225, 2012.

[24] Cynthia Putnam, Maria Dahman, Emma Rose, Jinghui Cheng, and Glenn Bradford, "Teaching Accessibility, Learning Empathy," Proceedings of the 17th International ACM SIGACCESS Conference on Computers \& Accessibility, Lisbon, Portugal, 333-334, 2015.

[25] Stephanie Ludi, Matt Huenerfauth, Vicki Hanson, Nidhi Rajendra Palan, and Paula Garcia, "Teaching inclusive thinking to undergraduate students in computing programs," Proceedings of the 49th ACT Technical Symposium on Computer Science Education, pp. 717-722, Baltimore MD, USA, 2018.

[26] David M. Richter, Marie C. Paretti, "Identifying barriers to and outcomes of interdisciplinarity in the engineering classroom," European Journal of Engineering Education 34, no.1 (2009): 29.

[27] Diana Stentoft, "From saying to doing interdisciplinary learning: Is problem-based learning the answer?" Active Learning in Higher Education 18, no.1(2017): 51-61. 